\title{
Evidence for "lumen sealing" with sirolimus eluting stents in the treatment of complex coronary artery dissection
}

\author{
E M Wong, C Pawsey, H C Lowe
}

Heart 2004;90:e13 (http://www.heartjnl.com/cgi/content/full/90/3/e13). doi: 10.1136/hrt.2003.026609

Immediate and two month angiographic and intravascular ultrasound examination of sirolimus eluting stents deployed for complex coronary dissection is presented. The findings support the hypothesis that this novel treatment option is both effective and safe.

A 73 year old woman underwent stenting to a presumed spontaneous, complex right coronary artery dissection. She had presented with ventricular tachycardia. Her history included inferior myocardial infarction, moderately severe regional left ventricular impairment, and otherwise minor coronary artery disease.

The right coronary artery dissection extended almost from the ostium to the mid-vessel, with preserved TIMI (thrombolysis in myocardial infarction) 3 flow distally ${ }^{1}$ (fig lA). After predilatation two sirolimus eluting stents were deployed (Cypher $3.0 \times 13 \mathrm{~mm}$ and $2.5 \times 28 \mathrm{~mm}$, Cordis Corp, Warren, New Jersey, USA) with minimal overlapping, ensuring complete coverage of the dissected segment (fig 1B). This resulted in angiographic evidence of a residual false lumen (fig 1B), confirmed by intravascular ultrasound (fig 1C). It was elected not to proceed with further stent dilatation into this false lumen, and the patient was treated with aspirin and clopidogrel. An implantable defibrillator was also inserted for inducible, sustained monomorphic ventricular tachycardia.

At two months' follow up, intravascular ultrasound suggested a persisting residual space at the site of the prior false lumen (fig $\mathrm{IE}$ ) and minimal in-stent restenosis. Angiography however, showed an excellent result, with sealing of the communication with the false lumen, suggesting an appropriate persistent injury response (fig lD).

\section{DISCUSSION}

Conventional treatment of lengthy dissection-either spontaneous or iatrogenic-is provided by stenting the entire lesion length with bare metal or polytetrafluoroethylene covered stents. These are effective at sealing the dissection but are associated with high rates of restenosis. ${ }^{2-5}$

Sirolimus eluting stents recently entered widespread clinical practice, after much discussed trials obtained major reductions in restenosis for de novo native coronary lesions. ${ }^{6}$ The use of sirolimus eluting stents in wider patient and lesion subtypes is now being examined..$^{78}$ Their use in the elective treatment of lengthy dissections has not been described.

In animal models of balloon injury, sirolimus is associated with increased apoptosis in the vessel wall. ${ }^{9}$ Preliminary human clinical data suggest increased rates of incomplete stent-strut apposition with sirolimus eluting stents compared with bare metal. ${ }^{10}$ These data, and past experience with "black holes" and aneurysm formation after intracoronary brachytherapy, ${ }^{11}{ }^{12}$ may suggest that sirolimus eluting stents may be detrimental in the setting of large unsealed dissection by contributing to incomplete vessel healing.

The experience presented here, however, does not support these concerns. Rather, it suggests that sirolimus eluting stents may be safely used in the setting of lengthy unsealed dissection and that they promote lumen sealing in much the same way as bare metal stents. Given the otherwise high restenosis rate expected with conventional treatment of lengthy dissection, we suggest that the use of sirolimus eluting stents in this context be further examined.

\section{ACKNOWLEDGEMENTS}

HCL is a Clinical Research Fellow of the NHMRC of Australia

\section{Authors' affiliations \\ E M Wong, C Pawsey, H C Lowe, Concord Repatriation General Hospital, Sydney, Australia}

Correspondence to: $\mathrm{Dr} \mathrm{H}$ C Lowe, Department of Cardiology, Concord Repatriation General Hospital, Sydney, Australia; h.lowe@unsw.edu.au

Accepted 2 October 2003

\section{REFERENCES}

1 Chesebro JH, Knatterud G, Roberts R, et al. Thrombolysis in myocardial infarction (TIMI) trial, phase I: a comparison between intravenous tissue plasminogen activator and intravenous streptokinase. Circulation 1987;76:142-54

2 Mushahwar SS, Pyatt JR, Lowe J. Clinical outcomes of long coronary stents: a single-center experience. Int J Cardiovasc Intervent 2001:4:29-33.

3 Abu-Ful A, Weinstein JM, Henkin Y. Covered stent: a novel percutaneous treatment of iatrogenic aortic dissection during coronary angioplasty. J Invasive Cardiol 2003;15:408-9.

4 Kachwalla $\mathrm{H}$, Lo STH, Tie $\mathrm{H}$, et al. Spontaneous coronary dissection following exertion: support for a hypothesis. Intern Med J $2001 ; 31: 501-3$.

5 Vale PR, Baron D. Coronary artery stenting for spontaneous coronary artery dissection: a case report and review of the literature. Cathet Cardiovasc Diagn 1998:45:280-6.

6 Morice MC, Serruys PW, Sousa JE, et al. A randomized comparison of a sirolimus-eluting stent with a standard stent for coronary revascularization. N Engl J Med 2002;346:1773-80.

7 Degertekin M, Regar E, Tanabe K, et al. Sirolimus-eluting stent for treatment of complex in-stent restenosis: the first clinical experience. J Am Coll Cardiol 2003;41:184-9.

8 Degertekin M, Regar E, Tanabe K, Sirolimus eluting stent in the treatment of atherosclerosis coronary artery disease, et al. Minerva Cardioangiol 2002;50:405-18.

9 Roque M, Cordon-Cardo C, Fuster V, et al. Modulation of apoptosis, proliferation, and p27 expression in a porcine coronary angioplasty model. Atherosclerosis 2000;153:315-22.

10 Serruys PW, Degertekin M, Morice MC, et al. Intravascular ultrasound findings in the randomized, double-blind RAVEL trial. Circulation 2002; 106:798-803.

11 Vandergoten $\mathbf{P}$, Brosens $M$, Benit $E$. Coronary aneurysm five months after intracoronary bet-irradiation. Acta Cardiol 2000;55:313-5.

12 Castagna MT, Mintz G, Weissman N, et al. "Black hole": echolucent restenotic tissue after brachytherapy. Circulation 2001;5:778. 


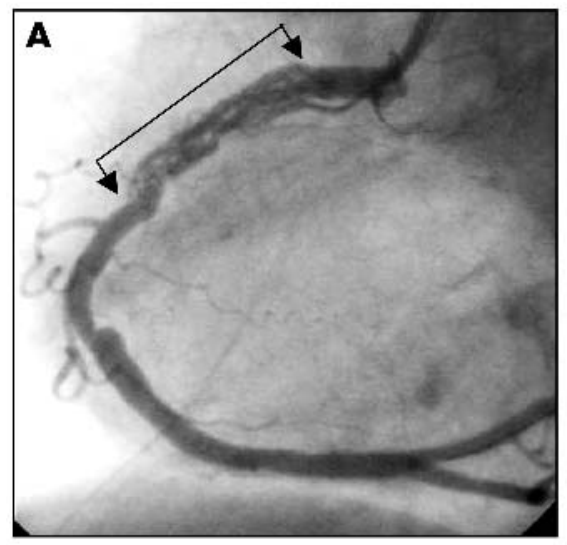

Figure 1 (A) Dissection is notable between arrows. (B) False lumen (FL) (vertical arrow). The area between the arrows is imaged $(C, D, E)$.
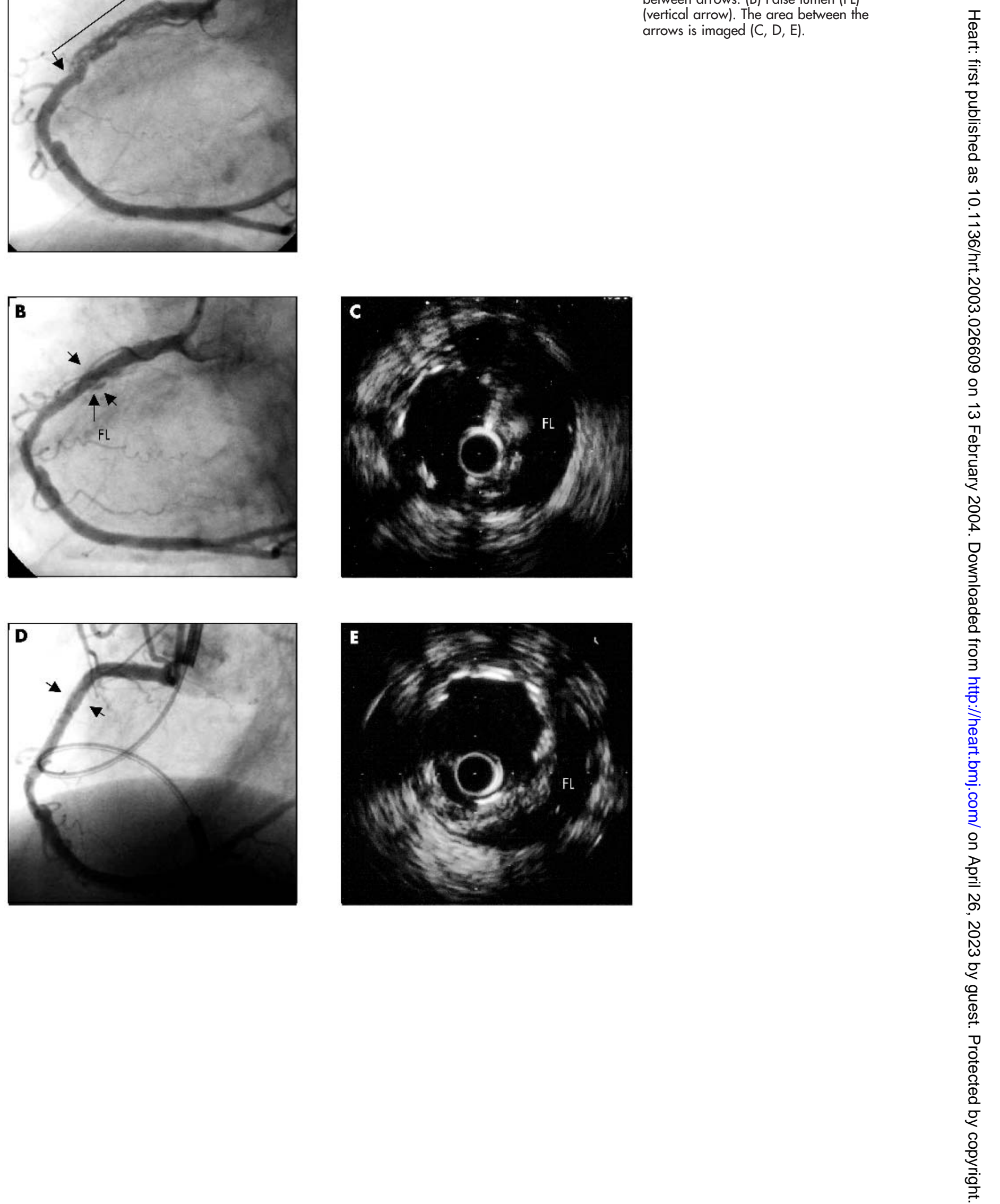